\title{
The Double-Edged Sword of Automating Personalized Interventions in Makerspaces: An Exploratory Study of Potential Benefits and Drawbacks
}

\author{
Edwin Chng ${ }^{(凶)}$, Sofya Zeylikman, and Bertrand Schneider \\ Harvard University, Cambridge, MA 02138, USA \\ chng_weimingedwin@g. harvard.edu, \\ szeylikman@gmail.com, \\ bertrand_schneider@gse.harvard.edu
}

\begin{abstract}
While the affordance of a project-based and instructor-facilitated curriculum is a strength of makerspaces, they can be challenging learning environments for many students. This paper recognizes the need for instructors to personalize their approach in supporting students' needs. While there are opportunities to create automated systems to help instructors personalize their interventions, much care must be taken to prevent the introduction of unintended outcomes. In this study, we designed a weekly personalized intervention cycle based on students' self-reports. The effect of such personalized intervention was then evaluated using a repeated measure ANOVA. Findings suggest that students receiving personalized interventions were more time efficient in makerspaces and on assignments. Additionally, they reported a lower level of frustration. Students with personalized intervention, however, expressed a lower sense of community. This suggests that while additional data provided to instructors can support personalized assistance, a more nuanced approach may be needed to avoid unintended consequences.
\end{abstract}

Keywords: Personalized intervention - Makerspaces - Instructional support

\section{Introduction}

The dynamic nature of makerspaces can present challenges for instructors. In particular, students enter makerspaces from diverse backgrounds. This includes different levels of prior expertise, learning attitudes and working styles. Catering to students' learning needs is an almost impossible task without a good understanding of their individual backgrounds. The use of technology can support instructors in this area by aggregating relevant student information for the instructors to act on. However, cautionary tales from recent debates on algorithmic bias suggest that much consideration ought to be undertaken before committing to the design of a fully automated system for personalization. Therefore, the goal of this work is to conduct preliminary investigations into the design of a personalized intervention cycle to derive a more nuanced understanding of the effects of automated personalization. 


\section{Literature Review}

A close examination of the benefits of makerspaces by Clapp et al. [1] indicates that the benefits of makerspaces lie in the development of students" "maker's mindset", which includes the development of a sense of agency and community spirit. The authors argue that, beyond the immediate transfer of technical skills, makerspaces imbue students with social-emotional skills and the ability to work in cross-disciplinary teams.

However, there are barriers to student learning in makerspaces [2]. For instance, students with little technical background might find entering the space to be daunting or encounter much difficulty when troubleshooting their projects. To complicate matters even further, diverse populations enter makerspaces with different levels of prior experience and expertise, abilities to seek help, and attitudes towards learning [3, 4]. This leads to an impossibility of a one-size-fits-all approach in teaching instruction. When facilitators provide personalized support, students not only overcome their difficulties more easily, but they also feel a greater sense of empowerment, which is critical for students who find makerspaces intimidating [5].

Despite the purported benefits of personalized instruction and maker-centered learning on a diverse population of students, we lack research-based guidelines for implementing this kind of instruction [2]. Thus, this research aims to derive a more nuanced understanding of personalization before the implementation of an automated personalization system.

\section{Overview}

\subsection{Course Overview}

Students in the digital fabrication course learn about digital fabrication tools like the use of basic electronics, microcontrollers, and laser cutters. In total, 24 graduate level students participated in this research study. The course is conducted at a makerspace located on the campus of a university in the northeastern United States.

\subsection{Research Questions}

Through conducting this study, we sought to understand the effect of personalized interventions on a student's learning experience as well as their maker's mindset. A student's learning experience encompasses a self-reflection of the student's mood, technical ability, and connection to others in the space. The maker's mindset includes a sense of agency and community [1]. Thus, our research questions are as follows:

1. What is the effect of personalized interventions on student learning experience?

2. What is the effect of personalized interventions on students' maker mindset? 


\section{Methods}

We conducted a study in which a teaching team consisting of two co-instructors, two teaching assistants, and a lab manager were provided with information about 24 different students' individualized learning profiles. The effect of personalized interventions was studied by differentiating the information provided in these learning profiles. For students not receiving personalized interventions, their learning profiles included minimal information and simply stated the learning challenges encountered by each student. On the other hand, for students receiving personalized interventions, their profiles included specific interventions related to their learning challenges, as well as an overview of the students' individual learning progress. The suggested interventions were manually selected from an "intervention database" that contains suggestions from 32 makerspace facilitators and the overview of students' learning progress was automatically created using data collected from weekly and monthly student surveys. This formed the basis of our semi-automated approach. To determine the effect of personalization on students, we conducted a one-way ANOVA with repeated measures on the standardized survey scores.

\section{Results}

\subsection{RQ 1 - Personalization Leads to Student Time Efficiency and Less Frustration in Learning}

Table 1 shows the results for the dimensions of the student learning experience captured from weekly surveys that has statistically significant results between groups of students with and without personalized intervention. Based on the statistical analysis, we find that with personalized intervention, students spent significantly less time within the makerspace and on assignments. Students who received personalized intervention were also, on average, less frustrated than their peers.

Table 1. Effect of personalized intervention on student learning experience

\begin{tabular}{l|l|l|l}
\hline $\begin{array}{l}\text { Dimension of } \\
\text { learning } \\
\text { experience }\end{array}$ & $\begin{array}{l}\text { One-way ANOVA with } \\
\text { repeated measures }(\mathrm{n}=24)\end{array}$ & $\begin{array}{l}\text { Personalized } \\
\text { intervention } \\
(\mathrm{n}=12)\end{array}$ & $\begin{array}{l}\text { General } \\
\text { feedback } \\
(\mathrm{n}=12)\end{array}$ \\
\hline Assignment time & $F(2,41)=8.01, p<0.01$ & -0.16 s.d. & 0.06 s.d. \\
\hline Makerspace time & $F(2,41)=5.44, p<0.05$ & -0.16 s.d. & 0.05 s.d. \\
\hline Frustration & $F(2,41)=6.34, p<0.05$ & -0.10 s.d. & 0.15 s.d. \\
\hline
\end{tabular}

\subsection{RQ 2 - Personalization Leads to Unexpected Lowering of Community Spirit}

The last research question looks at the effect of personalized interventions on students' maker mindset. The results of the statistical analysis indicate that personalized interventions had no statistically significant impact on students' sense of agency, but they 
affected students' sense of community spirit. The negative score for students receiving personalized intervention shows that, on average, students with personalized interventions had a lower sense of community spirit (Table 2).

Table 2. Effect of personalized intervention on maker's mindset

\begin{tabular}{l|l|l|l}
\hline Maker's mindset & $\begin{array}{l}\text { One-way ANOVA with } \\
\text { repeated measures }(\mathrm{n}=24)\end{array}$ & $\begin{array}{l}\text { Personalized } \\
\text { intervention }(\mathrm{n}=12)\end{array}$ & $\begin{array}{l}\text { General } \\
\text { feedback }(\mathrm{n}=12)\end{array}$ \\
\hline Agency & $F(2,41)=0.60, \mathrm{p}=0.4438$ & - & - \\
\hline Community spirit & $F(2,41)=6.87, \mathrm{p}<0.05$ & -0.07 s.d. & 0.09 s.d. \\
\hline
\end{tabular}

\section{Discussion}

We found that students spent less time in the makerspace and on their assignments after receiving personalized intervention. One possible explanation is that their learning challenges were addressed adequately by the instructors. As a result, they became more time efficient in completing their coursework. Becoming more time efficient may also explain why students with personalized intervention felt less frustrated as compared to their peers. This result suggests that the benefits of personalization goes beyond the cognitive aspects of helping students and might provide emotional relief as well.

The result that students with personalized intervention felt a lower sense of community spirit was unexpected. One interpretation is that when students become more time efficient as a result of personalization, they spend less time in the makerspace socializing with peers to troubleshoot their problems. While this result is unexpected, it gives warning that a more nuanced approach in personalization may be needed to avoid unintended consequences. This is an important concern, since communities building and sharing with peers is integral to developing a student's maker's mindset.

\section{Conclusion}

Our research showed that personalization is a feasible endeavor in makerspaces. The use of surveys, an intervention database, and a student profile allowed us to create a semi-automated system of personalization to augment instructor decision making. While we considered aspects of learning beyond just students' technical skills, our efforts to personalize concluded in students that were more time efficient and less frustrated, but less connected to their communities. This prompts additional questions on how personalization and automation can be further nuanced to achieve different learning objectives, and our research serves as the beginning foundation for heading in this direction. 


\section{References}

1. Clapp, E.P., Ross, J., Ryan, J.O., Tishman, S.: Maker-centered Learning: Empowering Young People to Shape their Worlds. Jossey-Bass, San Francisco (2016)

2. Litts, B.K.: Resources, facilitation, and partnerships: three design considerations for youth makerspaces. In: Proceedings of the 14th International Conference on Interaction Design and Children, pp. 347-350 (2015)

3. Sheridan, K., Halverson, E.R., Litts, B., Brahms, L., Jacobs-Priebe, L., Owens, T.: Learning in the making: a comparative case study of three makerspaces. Harv. Educ. Rev. 84(4), 505531 (2014)

4. Martinez, S.L., Stager, G.S.: The maker movement: a learning revolution. Learn. Lead. Technol. 41(7), 12-17 (2014)

5. Keefe, J.W., Jenkins, J.M.: Personalized instruction. Phi Delta Kappa Fastbacks 532(1-2), $7-$ 49 (2005) 